University of Nebraska - Lincoln

DigitalCommons@University of Nebraska - Lincoln

Faculty Papers and Publications in Animal

Science

Animal Science Department

July 2000

\title{
Parameter estimates for greasy fleece weight of Rambouillet sheep at different ages
}

\author{
J. W. Lee \\ University of Nebraska-Lincoln \\ D. F. Waldron \\ Texas Agricultural Experiment Station, Texas A\&M University, San Angelo \\ L. Dale Van Vleck \\ University of Nebraska-Lincoln, dvan-vleck1@unl.edu
}

Follow this and additional works at: https://digitalcommons.unl.edu/animalscifacpub

Part of the Animal Sciences Commons

Lee, J. W.; Waldron, D. F.; and Van Vleck, L. Dale, "Parameter estimates for greasy fleece weight of Rambouillet sheep at different ages" (2000). Faculty Papers and Publications in Animal Science. 219. https://digitalcommons.unl.edu/animalscifacpub/219

This Article is brought to you for free and open access by the Animal Science Department at DigitalCommons@University of Nebraska - Lincoln. It has been accepted for inclusion in Faculty Papers and Publications in Animal Science by an authorized administrator of DigitalCommons@University of Nebraska - Lincoln. 


\title{
Parameter estimates for greasy fleece weight of Rambouillet sheep at different ages ${ }^{1,2}$
}

\author{
J. W. Lee*, D. F. Waldron $\dagger^{, 3}$, and L. D. Van Vleck \\ *Department of Animal Science, University of Nebraska, Lincoln 68583-0908; †Texas Agricultural Experiment \\ Station, Texas A\&M University, San Angelo 76901-9714; and †USDA, ARS, \\ Roman L. Hruska U.S. Meat Animal Research Center, Lincoln, NE 68583-0908
}

\begin{abstract}
Variance components for greasy fleece weight in Rambouillet sheep were estimated. Greasy fleece weight was modeled either as repeated measurements on the same trait or as different traits at different ages. The original data were separated according to the age of the ewe at shearing into three classes; $1 \mathrm{yr}, 2$ and $3 \mathrm{yr}$, and older than $3 \mathrm{yr}$. An animal model was used to obtain estimates of genetic parameters with a REML algorithm. Total numbers of animals in pedigrees for the different age classes were 696, 729, and 573 , respectively, and 822 for the repeated measures model across ages. The animal model included direct genetic, permanent environmental, and residual environmental random effects and fixed effects for age of
\end{abstract}

ewe, shearing date as contemporary group, and number of lambs born. Days between shearings was used as a covariate. Single-trait analyses were initially done to obtain starting values for multiple-trait analyses. A repeated measures model across ages was also used. Estimates of heritability by age group were $.42, .50$, and .58 from three-trait (age class) analyses and for the repeated measures model the estimate was .57 . Estimates of genetic correlations between fleece yields for $1 \mathrm{yr}$ and 2 and $3 \mathrm{yr}, 1 \mathrm{yr}$ and $>3 \mathrm{yr}$, and 2 and $3 \mathrm{yr}$ and $>3$ yr classes were $.88, .89$, and .97 , respectively. These estimates of genetic correlations suggest that a repeated measures model for greasy fleece weight is adequate for making selection decisions.

Key Words: Genetic Correlations, Genotype Environment Interaction, Heritability

(O2000 American Society of Animal Science. All rights reserved.

J. Anim. Sci. 2000. 78:2108-2112

\section{Introduction}

Previous studies have reported estimates of heritabilities and genetic correlations for several traits in sheep (Shelton and Menzies, 1968; Vesely et al., 1970; Coelli et al., 1998). Fogarty (1995) summarized estimates of genetic parameters for live weight, wool, and reproduction traits. Ercanbrack and Knight (1998) estimated genetic trends in lamb and wool production as part of a study to investigate the effectiveness of four selection protocols for improving production. Their study compared the economic results of using these protocols in Rambouillet, Targhee, Columbia, and Polypay sheep. Falconer (1952) suggested that measurements of a genotype in different environments might be considered

\footnotetext{
${ }^{1}$ Published as paper no. 12745, Journal Ser., Nebraska Agric. Res. Div., Univ. of Nebraska, Lincoln 68583-0908.

${ }^{2}$ The authors gratefully acknowledge the contributions of Maurice Shelton and Don Spiller in flock management and data recording.

${ }^{3}$ Correspondence: 7887 US Highway 87 N. (phone: 915/653-4576; fax: 915/658-4364; E-mail: d-waldron@tamu.edu).

Received August 23, 1999.

Accepted March 3, 2000.
}

separate traits. If the genetic correlations are less than .80 , selection might be more effective if the trait is defined by the environment where it is expressed (Falconer, 1952; Robertson, 1959). Okut et al. (1999) estimated the genetic correlations between expressions of genotypes at different ages of animal for wool traits for Columbia, Polypay, Rambouillet, and Targhee sheep. Coelli et al. (1998) reported estimates of heritabilities and genetic correlations for greasy fleece weight at different ages for Australian Merino sheep. The objective of this study was to determine whether greasy fleece weights at different ages in Rambouillet ewes should be considered as repeated measurements on a single trait or as different traits.

\section{Materials and Methods}

A flock of Rambouillet sheep was maintained by the Texas Agricultural Experiment Station at a ranch in Edwards County, Texas. The ewes were representative of the Rambouillet population in Texas. Flock management was typical for commercial conditions in the area except that single-sire breeding pastures were used and all lambing occurred in a barn to facilitate accurate pedigree records. Ewes were typically exposed for 
Table 1. Summary of observations, unadjusted means, and standard deviations (SD) for greasy fleece weight $(\mathrm{kg})$ by age of ewe class

\begin{tabular}{lcccc}
\hline \hline & \multicolumn{4}{c}{ Age of ewe class (yr) } \\
\cline { 2 - 5 } Item & 1 & 2 and 3 & $>3$ & \multicolumn{1}{c}{ All } \\
\hline Mean & 3.62 & 4.37 & 4.26 & 4.16 \\
SD & .84 & .87 & .88 & .91 \\
Records & 542 & 885 & 898 & 2,325 \\
Ewes & 542 & 577 & 413 & 691 \\
Sires & 42 & 40 & 47 & 60 \\
Dams & 306 & 322 & 253 & 370 \\
\hline
\end{tabular}

breeding from August to October, with subsequent lambing from January to March. All lambs were identified with their dam and ear-tagged within $18 \mathrm{~h}$ of birth. All lambs were weaned on the same day within a year when lambs averaged approximately $100 \mathrm{~d}$ of age.

Greasy fleece weights from the Rambouillet flock were collected from 1978 through 1998. Actual fleece weights were adjusted to a 365-d growth period. Fleece weight was divided by number of days from the previous shearing and multiplied by 365 . For the first shearing, the number of days since birth was used. Most shearing dates were in April or May. All ewes were shorn for the first time at about 14 mo of age. At the 14-mo shearing, all ewes were shorn on the same day, within each year.

Three data sets were generated from the original data file to analyze three different age classes separately. Records were divided by the age of ewe into three classes: ages of $1 \mathrm{yr}, 2$ and $3 \mathrm{yr}$, and older than $3 \mathrm{yr}$. The ages of ewe classes were the same categories as used by Okut et al. (1999). Number of days between shearings (or to first shearing) was fitted as a covariate to account for non-linearity of the adjustment to $365 \mathrm{~d}$. Analyses were also done without this covariate. Age of ewe, calendar day at shearing (as an indicator of contemporary group), and number of lambs born between shearings were fixed factors for all models. Number of lambs weaned would have been preferred to number of lambs born but was not available for most of the years. Total numbers of animals in pedigrees for the age 1 , age 2 and 3 , and age $>3$ yr classes were 696 , 729 , and 573, respectively, and 822 for the repeated records model across ages. Numbers of records and unadjusted means and standard deviations by age class of ewes are in Table 1.

A single-trait animal model was initially used to establish starting values for multiple-trait models as well as for the repeated measures model for all observations. The full single-trait model was

$$
\mathbf{y}=\mathrm{X} \boldsymbol{\beta}+\mathrm{Z} \mathbf{a}+\mathrm{W} \mathbf{p}+\mathbf{e}
$$

where $\mathbf{y}$ is a $\mathrm{N} \times 1$ vector of observations

$\boldsymbol{\beta}$ is vector of fixed effects (age of ewe, contemporary group, number of lambs born, and covariate of days between shearings)

$\mathbf{a}$ is vector of additive genetic effects

$\mathbf{p}$ is vector of uncorrelated permanent environmental effects

e is vector of residual effects, with $\mathrm{X}, \mathrm{Z}$, and $\mathrm{W}$ known matrices relating observations in $\mathbf{y}$ to vectors of fixed and random effects

For the model,

$$
\mathrm{E}[\mathbf{y}]=\mathrm{X} \boldsymbol{\beta} \quad \text { and }
$$

$$
V\left[\begin{array}{l}
\mathbf{a} \\
\mathbf{p} \\
\mathbf{e}
\end{array}\right]=\left[\begin{array}{ccc}
\mathbf{A} \sigma_{\mathrm{a}}^{2} & \mathbf{0} & \mathbf{0} \\
\mathbf{0} & \mathbf{I}_{\mathrm{N}_{\mathrm{a}}} \sigma_{\mathrm{p}}^{2} & \mathbf{0} \\
\mathbf{0} & \mathbf{0} & \mathbf{I}_{\mathrm{N}} \sigma_{\mathrm{e}}^{2}
\end{array}\right]
$$

where

$$
\begin{aligned}
\mathrm{N}_{\mathrm{a}} & =\text { number of ewes } \\
\mathrm{N} & =\text { number of records } \\
\mathrm{A} & =\text { numerator relationship matrix among an- } \\
& \text { imals in the pedigree file } \\
\mathrm{I} & =\text { identity matrix of appropriate order }
\end{aligned}
$$

The environmental covariance due to permanent environmental effects of ewes in the different age classes can be forced into the structure of covariance of permanent environmental effects across age classes even though ewes in the first age class can have only one measurement (Okut et al., 1999). The correlation between total (including residual and permanent) environmental effects can be calculated from the sum of the residual and permanent environmental variance components. The total environmental covariance between measures in two different age classes was computed as

$$
r_{e_{i j}}=\frac{r_{p_{i j}} \sqrt{p_{i}^{2} \times p_{j}^{2}}}{\sqrt{\left(p_{i}^{2}+e_{i}^{2}\right)\left(p_{j}^{2}+e_{j}^{2}\right)}}
$$

where

$$
\begin{aligned}
\mathrm{r}_{\mathrm{e}_{\mathrm{ij}}}= & \text { the correlation between total (residual and } \\
& \begin{array}{l}
\text { permanent) environmental effects for } \\
\\
\text { measurements of a ewe in age classes } i
\end{array} \\
& \text { and } j, \\
\mathrm{r}_{\mathrm{p}_{\mathrm{ij}}=} & \text { the correlation between permanent envi- } \\
& \text { ronmental effects for age classes } i \text { and } j \\
\mathrm{p}_{\mathrm{i}}^{2}= & \text { fraction of variance due to permanent en- } \\
& \text { vironmental effects for age class } i \\
\mathrm{p}_{\mathrm{j}}^{2}= & \text { fraction of variance due to permanent en- } \\
& \text { vironmental effects for age class } j
\end{aligned}
$$


Table 2. Estimates of variance components and genetic parameters (standard errors) for greasy fleece weight from single-trait analyses by age of ewe class and for a repeated measures model across ages (all)

\begin{tabular}{lcccc}
\hline \hline & \multicolumn{4}{c}{ Age of ewe class (yr) } \\
\cline { 2 - 5 } Parameter $^{\mathrm{a}}$ & 1 & 2 and 3 & $>3$ & All \\
\hline$\sigma_{\mathrm{a}}^{2}$ & 1.00 & 1.61 & 1.79 & 1.58 \\
$\sigma_{\mathrm{p}}^{2}$ & & .11 & .41 & .18 \\
$\sigma_{\mathrm{e}}^{2}$ & 1.08 & 1.03 & .69 & 1.01 \\
$\sigma_{\mathrm{y}}^{2}$ & 2.08 & 2.75 & 2.90 & 2.77 \\
$\mathrm{~h}_{\mathrm{a}}^{2}$ & .48 & .59 & .62 & .57 \\
& $(.097)$ & $(.072)$ & $(.083)$ & $(.056)$ \\
$\mathrm{p}^{2}$ & & .04 & .14 & .07 \\
& & $(.061)$ & $(.072)$ & $(.042)$ \\
$\mathrm{e}^{2}$ & .52 & .37 & .24 & .36 \\
& $(.097)$ & $(.037)$ & $(.024)$ & $(.023)$ \\
\hline
\end{tabular}

${ }^{\mathrm{a}} \sigma_{\mathrm{a}}^{2}=$ direct genetic variance, $\sigma_{\mathrm{p}}^{2}=$ variance due to permanent environmental effects, $\sigma_{\mathrm{e}}^{2}=$ variance of residual effects, $\sigma_{\mathrm{y}}^{2}=$ phenotypic variance, $h_{a}^{2}=$ direct heritability, $p^{2}=$ fraction of variance due to permanent environmental effects, and $\mathrm{e}^{2}=$ fraction of variance due to residual effects.

$\mathrm{e}_{\mathrm{i}}^{2}=$ fraction of variance due to residual effects for age class $i$

$\mathrm{e}_{j}^{2}=$ fraction of variance due to residual effects for age class $j$

Estimates of genetic parameters were obtained with a derivative-free algorithm for REML (Boldman et al., 1995). The program was restarted with estimates at previous apparent convergence as initial values until a global minimum was found (i.e., minus twice the logarithm of the likelihood did not change to the third decimal after consecutive restarts).

For multiple-trait analyses, this model was expanded to include covariances between additive genetic and permanent environmental effects in different age classes but with residual covariances assumed to be zero.

Repeatability for the repeated measures model was estimated as (additive genetic variance + permanent environmental variance)/phenotypic variance.

\section{Results and Discussion}

\section{Single-Trait Analyses}

Parameter estimates from single-trait analyses by age classes for greasy fleece weight are shown in Table 2. Estimates of heritabilities by age classes for greasy fleece weight gradually increased with age of ewes (.48, .59 , and .62) with an intermediate estimate for the repeated measures model (.57). Except for age of ewe class 1 , the estimates were the same whether or not days in shearing period was included in the model as a covariate. Including the covariate of days to first shearing reduced the heritability estimate for age class 1 from
.50 to .48. These estimates agreed well with those of Okut et al. (1999), who reported estimates of heritabilities for the same age classes for greasy fleece weight for Rambouillet sheep to be $.50, .68$, and .68, respectively. The estimates were greater than those of Bassett et al. (1967), who reported an estimate of heritability for greasy fleece weight to be .11 for Rambouillet sheep. Fogarty (1995) reported mean heritabilities of .35 and .36 for greasy and clean fleece weight, respectively, and weighted average genetic and phenotypic correlations between greasy and clean fleece weights of .84 and .88, respectively, in an extensive review of published parameter estimates. Therefore, literature estimates of both greasy and clean fleece weights are discussed together. Saboulard et al. (1995) estimated direct heritabilities for clean fleece weight to be .60 also for Rambouillet sheep. Vesely et al. (1970) estimated heritability to be .31 for greasy fleece weight and to be .23 for clean fleece weight for Rambouillet sheep. Shelton and Menzies (1968) obtained estimates of heritabilities to be .58 by the paternal half-sib method and .52 by the dam-offspring regression method for mean greasy fleece weight for Rambouillet sheep.

Estimates of relative variance due to total (including permanent and residual) environmental effects were $.52, .41$, and .38 , for the last three age classes and .43 for the analysis over all ages. These estimates agreed with those of Okut et al. (1999) who reported the fraction of variance due to both environmental effects for the same age classes for greasy fleece weight in Rambouillet sheep to be $.50, .33$, and .32 , respectively.

Estimate of heritability for greasy fleece weight when observations were considered as repeated measurements of the same trait was .57. Repeatability was .64. The heritability estimate reflects the average of estimates for the three age classes. Comparison of the heritability and repeatability estimates shows that genetic value of the ewe is much more important than permanent environmental effect of ewe for greasy fleece weight.

\section{Multiple-Trait Analyses}

Parameter estimates for two-trait and three-trait analyses for fleece weight are shown in Tables 3 and 4. Estimates of correlations among total environmental effects from the two-trait analyses were .21 for $1 \mathrm{yr}$ with 2 and $3 \mathrm{yr}, .07$ for $1 \mathrm{yr}$ with $>3 \mathrm{yr}$, and .36 for 2 and $3 \mathrm{yr}$ with $>3 \mathrm{yr}$. Estimates of direct heritability by age class for the three-trait analysis were $.42, .50$, and .58 , respectively. These estimates were somewhat less than with two-trait analyses, which were somewhat less than with single-trait analyses. These results agree with those of Coelli et al. (1998), who reported heritabilities for fleece weight to be .37 for $1 \mathrm{yr}, .40$ for $2 \mathrm{yr}, .49$ for $3 \mathrm{yr}, .48$ for $4 \mathrm{yr}$, and .47 for $5 \mathrm{yr}$ age classes for Australian Merino sheep. For two-trait analyses, estimates of genetic correlations between $1 \mathrm{yr}$ and 2 and $3 \mathrm{yr}, 1 \mathrm{yr}$ and $>3 \mathrm{yr}$, and 2 and $3 \mathrm{yr}$ and $>3 \mathrm{yr}$ classes 
Table 3. Parameter estimates from two-trait (age of ewe classes) analyses for greasy fleece weight

\begin{tabular}{|c|c|c|c|c|c|c|c|c|c|c|c|}
\hline \multicolumn{2}{|c|}{ Trait (age) } & \multirow[b]{2}{*}{$\sigma_{\mathrm{y}_{1}}^{2}$} & \multirow[b]{2}{*}{$\sigma_{\mathrm{y}_{2}}^{2}$} & \multirow[b]{2}{*}{$\mathrm{h}_{\mathrm{a}_{1}}^{2}$} & \multirow[b]{2}{*}{$\mathrm{h}_{\mathrm{a}_{2}}^{2}$} & \multirow[b]{2}{*}{$\mathrm{r}_{\mathrm{a}_{1} \mathrm{a}_{2}}$} & \multirow[b]{2}{*}{$\mathrm{p}_{1}^{2}$} & \multirow[b]{2}{*}{$\mathrm{p}_{2}^{2}$} & \multirow[b]{2}{*}{$\mathrm{e}_{1}^{2}$} & \multirow[b]{2}{*}{$\mathrm{e}_{2}^{2}$} & \multirow[b]{2}{*}{$\mathrm{r}_{\mathrm{e}_{1} \mathrm{e}_{2}}$} \\
\hline 1 & 2 & & & & & & & & & & \\
\hline 1 & 2 and 3 & 2.05 & 2.84 & .45 & .61 & .90 & .41 & .03 & .14 & .36 & .21 \\
\hline 1 & $>3$ & 2.08 & 3.08 & .47 & .68 & .93 & .43 & .10 & .09 & .22 & .07 \\
\hline 2 and 3 & $>3$ & 2.69 & 2.81 & .50 & .57 & .97 & .15 & .19 & .35 & .25 & .36 \\
\hline
\end{tabular}

were $.90, .93$, and .97 , respectively, which are highly positive. For three-trait analyses, estimates of genetic correlations between $1 \mathrm{yr}$ and 2 and $3 \mathrm{yr}, 1 \mathrm{yr}$ and $>3$ $\mathrm{yr}$, and 2 and $3 \mathrm{yr}$ and $>3$ yr classes were slightly smaller but still large; .88, .89, and .97, respectively. These estimates of genetic correlations among age classes were greater than those Okut et al. (1999) reported between the same age classes for Rambouillet sheep at the U.S. Sheep Experiment Station of .76, .74, and .94, respectively. These results also agree with those of Coelli et al. (1998), who reported genetic correlations between $2 \mathrm{yr}$ and older than $2 \mathrm{yr}$ age classes for fleece weight in Australian Merino sheep to be greater than .88 .

The guideline of Robertson (1959) is that, if the genetic correlation between traits is greater than 80 , then the trait need not be divided into separate traits defined by age class. The genetic correlations among greasy fleece weight in the three age classes indicate that selection for increasing fleece weight at young ages would result in increasing fleece weight at older ages. The large estimates of genetic correlations indicate that greasy fleece weights could be modeled as repeated measurements rather than separately by age class. These results agree with the recommendation of Okut et al. (1999) that fleece weight measured at different ages be considered as one trait. The estimates of heritability and of total variance, however, in this study were smaller for the $1 \mathrm{yr}$ class than for the two older age classes. Thus, some consideration might be given to age classes of $1 \mathrm{yr}$ and $>1 \mathrm{yr}$ or to standardizing phenotypic variance across ages.

Fixed Effects of Number of Lambs Born and Days Between Shearings

The estimated effect of producing twin lambs, compared with producing a single lamb, on the weight of fleece being grown at the time of parturition was -.26 $\pm .10 \mathrm{~kg}(P<.05)$ for 2 - and 3 -yr-old ewes and $-.26 \pm$ $.08 \mathrm{~kg}(P<.05)$ for ewes older than $3 \mathrm{yr}$. These estimates are higher than those of Snowder and Shelton (1988), who reported that Rambouillet ewes that weaned two lambs had .14 kg less greasy fleece weight than did ewes that raised a single lamb. Ray and Sidwell (1964) reported that the effects of lactation were greater than those of pregnancy in reducing wool production of Navajo and Targhee ewes. Because records of the number of lambs weaned were not available for this flock, the number of lambs born was the best available predictor of number of lambs weaned. The estimated effects of producing an additional lamb in the present study were within the range of estimates in the review of Corbett (1979).

The regression of greasy fleece weight on days between shearings was significant $(.0203 \pm .0053)$ for the

Table 4. Parameter estimates from three-trait (age of ewe classes) analyses for greasy fleece weight

\begin{tabular}{|c|c|c|c|c|c|c|c|}
\hline \multirow[b]{2}{*}{ Trait (age) } & \multirow[b]{2}{*}{$\sigma_{\mathrm{y}}^{2 \mathrm{a}}$} & \multirow[b]{2}{*}{$\mathrm{h}^{2 \mathrm{~b}}$} & \multirow[b]{2}{*}{$\mathrm{p}^{2 \mathrm{c}}$} & \multirow[b]{2}{*}{$\mathrm{e}^{2 \mathrm{~d}}$} & \multicolumn{3}{|c|}{ Correlation matrix ${ }^{\mathrm{e}}$} \\
\hline & & & & & 1 & $2 \sim 3$ & $>3$ \\
\hline 1 & 2.01 & .42 & .45 & .12 & & .88 & .89 \\
\hline $2 \sim 3$ & 2.75 & .50 & .16 & .33 & .29 & & .97 \\
\hline$>3$ & 2.88 & .68 & .19 & .24 & .24 & .37 & \\
\hline \multicolumn{8}{|c|}{${ }^{\mathrm{a}} \sigma_{\mathrm{y}}^{2}=$ phenotypic variance. } \\
\hline \multicolumn{8}{|c|}{$\begin{array}{l}\sigma_{\mathrm{y}}^{\mathrm{a}}=\text { phenotypic varıance } \\
{ }^{\mathrm{b}} \mathrm{h}^{2}=\text { heritability. }\end{array}$} \\
\hline \multicolumn{8}{|c|}{${ }^{c} p^{2}=$ fraction of variance due to permanent residual effects. } \\
\hline \multicolumn{8}{|c|}{${ }^{d} \mathrm{e}^{2}=$ fraction of variance due to residual effects. } \\
\hline
\end{tabular}


age class of $1 \mathrm{yr}(P<.05)$ but was not significant for the older than $1 \mathrm{yr}$ age classes $(P>.05)$. This result suggests that the linear adjustment of fleece weight to a constant $365 \mathrm{~d}$ is not adequate for the 1-yr-old ewe class in this study, perhaps because of the large increases in body weight during the time first fleece is grown.

\section{Implications}

Estimates of genetic correlations among genetic expressions of greasy fleece weight at different ages were highly positive. Estimates of direct heritabilities were large. Thus, greasy fleece weight does not need to be defined into several age classes for genetic evaluation. Whether a ewe produces one or two lambs should be taken into account in genetic evaluations because lamb production does have a significant effect on fleece weight. This study suggests that a repeated measures model for greasy fleece weight is adequate for genetic evaluation.

\section{Literature Cited}

Bassett, J. W., T. C. Cartwright, J. L. Van Horn, and F. S. Willson. 1967. Estimates of genetic and phenotypic parameters of weanling and yearling traits in range Rambouillet ewes. J. Anim. Sci. 26:254-260.

Boldman, K. G., L. A. Kriese, L. D. Van Vleck, C. P. Van Tassell, and S. D. Kachman. 1995. A manual for use of MTDFREML. A set of programs to obtain estimates of variances and covariances [DRAFT]. ARS, USDA, Washington, DC.
Coelli, K. A., A. R. Gilmour, and K. D. Atkins. 1998. Comparison of genetic covariance models for annual measurements of fleece weight and fibre diameter. In: Proc. 6th World Cong. Genet. Appl. to Livestock Prod., Armidale, Australia. 24:31-34.

Corbett, J. L. 1979. Variation in wool growth with physiological state. In: J. L. Black and P. J. Reis (ed.) Physiological and Environmental Limitations to Wool Growth. pp 79-98. Univ. New England Pub., Armidale, Australia.

Ercanbrack, S. K., and A. D. Knight. 1998. Responses to various selection protocols for lamb production in Rambouillet, Targhee, Columbia, and Polypay sheep. J. Anim. Sci. 76:1311-1325.

Falconer, D. S. 1952. The problem of environment and selection. Am. Nat. 86:293-298.

Fogarty, N. M. 1995. Genetic parameters for live weight, fat and muscle measurements, wool production and reproduction in sheep: A review. Anim. Breed. Abst. 63:101-143.

Okut, H, C. M. Bromley, L. D. Van Vleck, and G. D. Snowder. 1999. Genotypic expression at different ages: II. Wool traits of sheep. J. Anim. Sci. 77:2366-2371.

Ray, E. E., and G. M. Sidwell, 1964. Effects of pregnancy, parturition, and lactation upon wool production of range ewes. J. Anim. Sci. 23:989-994.

Robertson, A. 1959. The sampling variance of the genetic correlation coefficient. Biometrics. 15:469-485.

Saboulard, M., W. C. Russell, and M. L. Riley. 1995. Selection for lambing rate and clean fleece weight in sheep. J. Anim. Sci. 73:3195-3198.

Shelton, M., and J. W. Menzies. 1968. Genetic parameters of some performance characteristics of range fine-wool ewes. J. Anim. Sci. 27:1219-1223.

Snowder, G. D., and M. Shelton. 1988. The relationship of lamb and wool production in range Rambouillet ewes. Sheep Industry Development Program, Inc. Res. J. 4(3):1-5.

Vesely, J. A., H. F. Peters, S. B. Slen, and O. W. Robison. 1970. Heritabilities and genetic correlations in growth and wool traits of Rambouillet and Romnelet sheep. J. Anim. Sci. 30:174-181. 